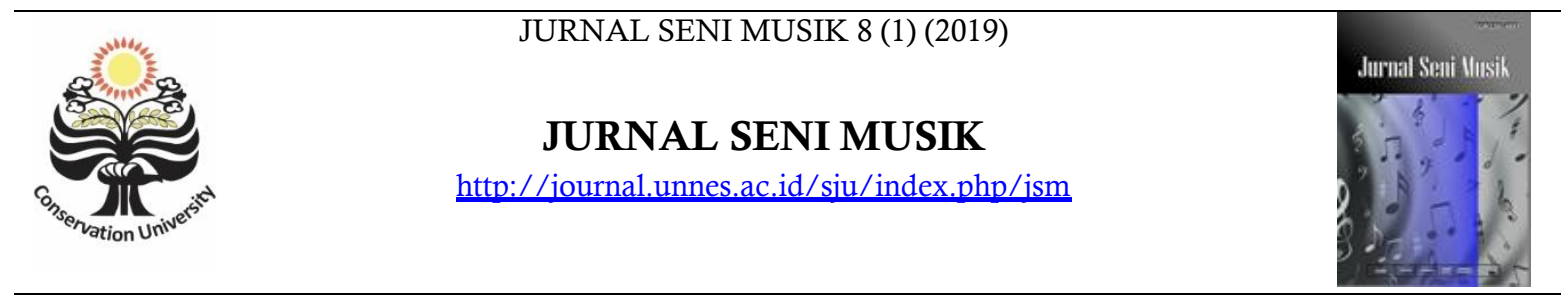

\title{
KOMPOSISI DAN ARANSEMEN MUSIK BABALU SEBAGAI SEBUAH KAJIAN MUSIKALITAS TRADISIONAL
}

\author{
Moh Faliqul Isbah \\ Joko Wiyoso
}

Jurusan Pendidikan Sendratasik, Fakultas Bahasa dan Seni, Universitas Negeri Semarang, Indonesia

\section{Info Artikel \\ Sejarah Artikel: \\ Diterima Oktober 2018 \\ Disetujui Maret 2019 \\ Dipublikasikan Juni 2019}

\section{Kata Kunci}

Komposisi Musik,

Aransemen, Babalu

Keyword

Music Composition, Arrangement,

Babalu

\begin{abstract}
Abstrak
Kesenian babalu merupakan singkatan dari kata aba-aba dahulu. Kesenian babalu jaman dahulu digunakan untuk melawan penjajah dengan menggunakan simbol-simbol yang telah disepakati oleh masyarakat setempat. Kesenian ini belum terse-dianya kajian yang jelas mengenai komposisi musik. Keunikan Komposisi Musik dan aransemen dalam Kesenian babalu merupakan alasan penulis mengambil tema Komposisi Musik dan aransemen dalam Kesenian babalu sebagai objek dalam penelitian ini. Kurangnya perhatian terhadap ketetapan Komposisi Musik dalam Kesenian babalu juga termasuk salah satu alasan lain penulis mengambil tema Kom-posisi Musik Iringan dalam Kesenian babalu. Rumusan masalah dalam penelitian ini adalah bagaimanakah konsep/ pandangan, ciri/ karakteristik, dan komposisi musik iringan dalam Kesenian babalu di Kabupaten Kendal. Kesimpulan dalam penelitian ini adalah kesenian babalu pada awalnya hanya menggunakan instrumen vokal saja, namun seiring perkembangan jaman kesenian ini mengalami penyesuaian yaitu aransemen, penelitian ini diharapkan dapat bermanfaat sebagai pengembangan teori mengenai Komposisi Musik Iringan yang dimiliki Kesenian babalu, sedangkan secara praktis penelitian ini bermanfaat sebagai masukan bagi seluruh warga masyarakat Kabupaten Batang mengenai pelestarian Kesenian babalu.
\end{abstract}

\section{Abstract}

Babalu art stands for the word aba-aba first. Babalu art used in ancient times to fight invaders by using symbols agreed upon by the local community. Babalu art was born in Batang District, Proyonanggan Tengah District. The uniqueness of Musik Composition and arrangement in Babalu Art is the reason the author takes the theme of Musik Composition and Arrangement in Babalu Art as an object in this study. The lack of attention to the provisions of Musik Composition in Babalu Health is also one of the other reasons the author takes the theme of Accompaniment Musik Composition in Babalu Art. The formulation of the problem in this study is how are the concepts / views, characteristics / composition, and composition of musikal accompaniment in Babalu Art in Kendal Regency. The research objective to be achieved in this study is to find out, analyze, and describe the concepts / views, characteristics, and accompaniment of musikal compositions used in babalu art in Batang regency. Theoretically, this research is expected to be useful as a theory de-velopment regarding Accompaniment Musik Composition that belongs to Babalu Art, while practically this research is useful as input for all residents of Batang Re-gency regarding the conservation of Babalu Art.

(C) 2019 Universitas Negeri Semarang

\footnotetext{
$\triangle$ Jurusan Pendidikan Sendratasik, FBS

Universitas Negeri Semarang, Indonesia

Email: usmanwafa@mail.unnes.ac.id
} 


\section{PENDAHULUAN}

Kesenian adalah bagian dari budaya yang merupakan sarana yang digunakan untuk mengekspresikan rasa keindahan dalam jiwa, kekaguman, dan rasa syukur kepada Tuhan yang Maha Esa . Indonesia merupakan Negara yang kaya akan keanekaragaman kesenian dan budaya. Keanekaragaman suku dan budaya daerah mengakibatkan timbulnya multikulturalnya kesenian. Kesenian sebagian bagian dari kebudayaan yang mempunyai ciri khusus yang menunjukkan sifat-sifat kedaerahan dari satu daerah dengan daerah lainnya. Menurut Oswald (Dalam Yeniningsih, 2007:216) Latar belakang kebudayaan di Indonesia dengan beragam kebudayaan daerah menjadikan Indonesia sebagai bangsa dengan kesenian yang heterogen. Inilah salah satu kekayaan bangsa Indonesia dalam bidang seni budaya dan terus berkembang dengan berpijak pada kesenian yaitu : seni rupa, seni tari, seni musik, seni sastra dan seni film. kebudayaan Indonesia sangat beragam karena penduduk Indonesia Multikultural. Hal ini di sebabkan kontur daerah di Indonesia sangat berbeda membuat penduduk Indonesia berkelompok. Dengan demikian, Penduduk di Indonesia memiliki berbagai macam wujud dan ragam kesenian daerah. Dalam perwujudannya, kesenian daerah lahir dengan ragam sejarah yang berbeda

Perkembangan kebudayaan menurut Tumbijo(1977:13) adalah seni budaya yang sejak lama turun temurun telah hidup dan berkembang pada daerah tertentu. Kebudayaan yang telah lama hidup dan berkembang di Indonesia diciptakan nenek moyang bangsa ini dan memiliki sifat turun temurun secara tradisional dari satu generasi ke generasi berikutnya. Dari proses pewarisan yang turun temurun inilah kebudayaan hidup dan berkembang sampai saat ini. Setiap suku bangsa di Indonesia memiliki jenis kebudayaan yang berbeda dengan kebudayaan yang berkembang pada suku-suku bangsa lainnyadi Negara ini. Dengan demikian, kebudayaan merupakan kekayaan dan ciri khas Kesenian babalu merupakan wujud kesenian daerah yang masih lestari sampai sekarang. Lahir dan berkembang di tanah jawa tengah, kesenian babalu dulunya hanya segelintir orang yang mengetahuinya. Namun di era sekarang, kesenian ini sudah banyak diketahui masyarakat umum. Meski berkembang dalam lingkaran musik modern, popularitas kesenian babalu tidak kian redup. Kesenian babalu masih banyak di jumpai pada acara-acara besar di kabupaten Batang. Namun apabila tidak di oprakoprak (dilestarikan) dengan serius, perkembangan musik-musik modern di khawatirkan akan dapat menenggelamkan kesenian babalu ini. Tanggapan masyarakat Batang sendiri senang dengan adanya kesenian babalu ini, karena kesenian babalu membawa dampak ketentraman dan kedamaian bagi masyarakat Batang. Selain itu kesenian babalu ucap kali dipakai untuk memeriahkan HUT kabupaten Batang kemudian mewakili lomba kesenian daerah kabupaten Batang pada Tahun 2016 kemudian tampil di TMII serta untuk penyambutan menteri dan tamu.

Kesenian babalu dulunya digunakan untuk memberikan kode rahasia kepada masyarakat Batang untuk menyerang penjajah yang sedang lengah dalam menikmati kesenian Babalu ini. Musik iringan didalam kesenian ini pun dulunya sangat sederhana, yaitu menggunakan alat perkusi, rebana dan kentongan. Namun pada masa era modern ini, Seni pertunjukan kesenian Babalu sudah mengalami penambahan instrument yaitu alat musik pentatonic seperti seperangkat gamelan dan diatonic alat musik modern.

Landasan teori dalam komposisi menurut Banoe (2003:426) unsur bentuk komposisi musik adalah frase, periode, bentuk lagu satu bagian, dua bagian tunggal, tiga bagian tunggal, dua bagian majemuk, rondo, tema dan variasi, sonata. Unsur komposisi musik adalah syair, ritme dan pola ritme, metrum, melodi, harmoni, dinamik, warna bunyi,tekstur. Unsur struktur komposisi musik adalah motif, tema, variasi (semua unsure komposisi dapat divariasi), improvisasi.

Dalam hal analisa terhadap suatu komposisi musik, mengenai kajian keseluruhan terhadap seluruh struktur musik. Kajian ini didasarkan pada latarbelakang, sejarah, perkembangan, strukturmusikal, sertaelemen-elemenmusik yang diteliti, agar dapat diperoleh karakteristik suatu komposisi musik secara tepat. Karakter musikal yang diperoleh pada dasarnya berfungsi untuk mengidentifikasikan, mendefinisikan dan mengklasifikasikan suatu komposisi musik tertentu.

Dalam hal aransemen menggunakan teori Kawaki (1975:260) ada beberapa elemen yang membentuk struktur itu antara lain :introduksi, chorus, interlute, variasi, ending, dan vamp.

\section{METODE}

Penelitian ini menggunakan metode kualitatif, menggunakan pendekatan seni dan pendekatan deskriptif. Lokasi penelitian ini disanggar Putra Budaya. Teknik pengumpulan data menguunakan teknik observasi, wawancara dan dokumentasi. Analisis data menggunakan reduksi data, penyajian data, dan penarikan kesimpulan

\section{HASIL DAN PEMBAHASAN}

\section{Kesenian di Kelurahan Proyonanggan Tengah}

Kesenian di daerah Batang memang cukup beragam.Adanya Sintren, Dengklung, Wayang Kulit, Ketoprak memang kadang dimainkan, namun jarang sekali dikembangkan, namun ada satu kesenian lagi yang masyarakat Batang belum tahu namun di 
kecamatan Proyonanggan tengah cukup di kenal, yaitu kesenian Babalu.

Kelurahan Proyonanggan terdapat sebuah kesenian yang sampai sekarang masih aktif melakukan kegiatan kesenian yaitu kesenian Babalu. Kesenian yang lain misal: Wayang Kulit, Sintren dan Kethoprak tidak berkembang di Kelurahan Proyonanggan. Apabila warga Kelurahan Proyonanggan ingin menanggap Wayang Kulit, Sintren dan Kethoprak yaitu dengan mendatangkan dari luar. Kesenian Babalu yang ada di Kelurahan Proyonanggan merupakan kesenian Babalu yang sudah berkembang, maksudnya dulu kesenian Babalu ditarikan oleh prajurit tetapi sekarang kesenian Babalu di lakukan oleh anak-anak tamat SLTA dan tamat akademik usia 18 - 35 tahun. Tamat akademikusia 25 - 35 yang sudah ahli dalam kesenian Babalu tersebut sekarang menjadi pelatih dan pengrawitnya atau pengiringnya saja.

\section{Sejarah Kesenian Babalu}

Kesenian Babalu berawal dari ide seorang seniman Batang yang mengingkan melawan penjajah tapi menggunakan kesenian. Dalam pelestarian kesenian Babalu terdapat salah satu sanggar yang menggembangkan kesenian Babalu, Sanggar Putra Budaya tepatnya di Kelurahan Proyonanggan juga berkembang kesenian yaitu kesenian Babalu.Kesenian Babalu sudah ada sebelum penjajah masuk di Kota Batang, pada jaman penjajah belum masuk di Kabupaten Batang, di Kabupaten Batang sangat subur.Oleh karena itu mata pencaharian masyarakat sekitar kebanyakan petani, setelah para penjajah masuk dan menguasai Kabupaten Batang keadaan penduduk di Kabupaten Batang semakin mengkhawatirkan.Banyak penduduk yang disiksa dan dijadikan budak, Bahkan para penduduk setiap bulan harus memberikan pajak berupa bahan pokok hasil budaya sendiri.

Perkembangan kesenian Babalu di Kabupaten Batang kian hari sangat mengkhawatirkan Pusat Pemerintahan di Kabupaten Batang sudah di kuasai oleh para penjajah, para pejuang di Kabupaten Batang tidak dapat bersatu yang dari Timur tidak bisa ke Barat, dari Barat juga tidak bisa ke Timur sebaliknya dari Selatan tidak bisa ke Utara, dari Utara tidak bisa ke Selatan karena empat penjuru mata angin sudah di kuasai oleh para penjajah.

Para pejuang yang berada di Kabupaten Batang berusaha mencari siasat perang yang tanpa harus bercucuran darah dan dapat mengalahkan penjajah dengan mudah. Maka terciptalah kesenian Babalu sebagai alat dan siasat untuk menggelabui penjajah dengan cara menari, para penari kesenian Babalu di bawakan oleh para gadis yang di rias sebagai prajurit, untuk menghibur para penjajah supaya lengah dan di suguhi minuman. Para penari member kode supaya para pejuang mudah masuk ke markas penjajah dengan siasat yang sudah di sepakati. Akhirnya para pejuang dapat mengalahkan para penjajah, penduduk Batang bersuka ria menyambut kemenangan dengan di tetapkan pada tanggal 8 April 1966 sebagai hari jadi Kota Batang.

\section{Komposisi Musik Iringan Kesenian Babalu}

Komposisi pada dasarnya analisa keseluruhan terhadap seluruh struktur musikal.Analisa ini didasarkan pada latar belakang, sejarah, perkembangan, struktur musikal, serta elemenelemen musik yang diteliti, agar dapat diperoleh karakteristik suatu komposisi musik secara tepat. Karakter musikal yang diperoleh pada dasarnya berfungsi untuk mengidentifikasikan, mendefinisikan dan mengklasifikasikan suatu komposisi musik tertentu. Berdasarkan suatu komposisi, ketika diperoleh suatu karakteristik komposisi musik tertentu, melalui analisa struktur, serta elemenelemen musik dalam suatu komposisi musik, maka dapat menghasilkan suatu susunan komposisi musik sesuai dengan aturan yang ditetapkan secara baik \& benar.

\section{BABALU MBATANG}

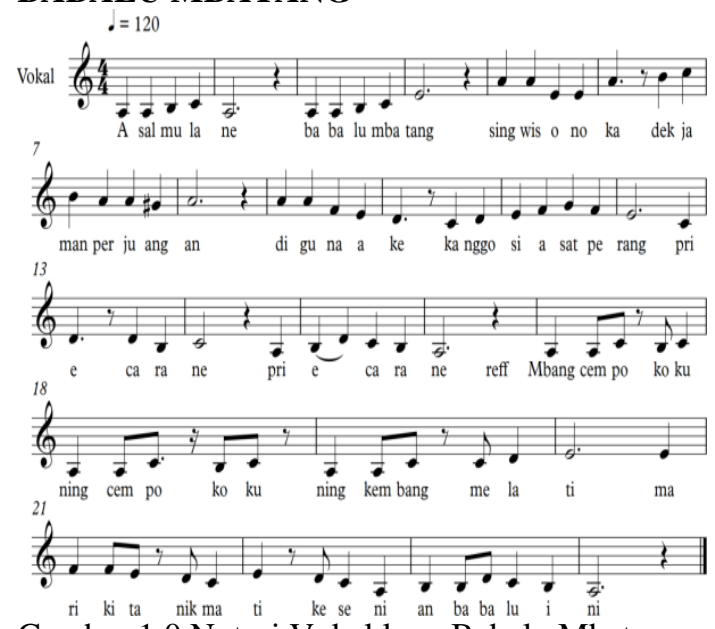

Gambar 1.0 Notasi Vokal lagu Babalu Mbatang

\subsection{Bentuk Lagu}

Menurut Wicaksono (2007:13-43) bentuk lagu dalam musik dibagi menjadi tiga macam, yaitu: 1 . Bentuk lagu satu bagian, 2. Bentuk lagu dua bagian, 3. Bentuk lagu 3 bagian. Bentuk lagu Babalu Mbatang pada komposisi awal pada kesenian Babalu hanya ada dua bagian. Dalam bentuk ini pada kalimat A diulangi dengan perubahan sebagai frase jawab kalimat A demikian juga frase tanya diulangi dengan perubahan sebagai frase jawab kalimat B.

\subsection{Syair}

Dalam menyanyikan sebuah lagu, berarti yang dinyanyikan adalah sebuah syair lagu.Tinggi rendahnya syair lagu yang dinyanyikan sesuai titinada-titinada dari notasi lagu tersebut, panjang 
pendeknya suku kata, dan kata dari syair lagu bergantung pada nilai titinada-titinada dan tanda istirahat dalam notasi lagu (Joseph, 2005: 57).

Berikut adalah lirik lagu kesenian Babalu.

Babalu Mbatang

Asal mulane Babalu mBatang

Sing wis ono kadek jaman perjuangan

Digunaake kangoo siasat perang

Pie carane pie menange

Mbang cepokokuning cepoko putih kembang melati

Mari kita nikmati kesenian Babalu ini.

Terjemahan gendhing

Babalu MBatang

Asal mulanya Babalu Batang Sudah ada dari zaman perjuangan

Di gunakan buat siasat perang

Gimana caranya gimana menangnya melati

Bunga cempaka kuning cempaka putih bunga

Mari kita nikmati kesenian Babalu ini.

bahwa syair musik iringan yang digunakan dalam Kesenian Babalu masih sederhana dan merupakan campuran dari bahasa Jawa dan Indonesia, dan menggunakan syair yang mudah dipahami kata-katanya, sehingga lebih mudah untuk diterima oleh para pendengar/penikmatnya.

\subsection{Tempo}

Tempo dibedakan menjadi 3 yaitu tempo lambat, tempo sedang, dan tempo cepat (Joseph, 2009: 59). komposisi pada musik iringan Babalu menggunakan tempo 120MM. berdasarkan wawancara diatas dapat di jelaskan bahwa musik iringan Babalu menggunakan tempo Allegro. Dari hasil penelitian yang sudah dilakukan, komposisi music iringan babalu menggunakan tempo cepat.

\subsection{Melodi}

Gerak nada-nada dalam melodi dibagi menjadi 2 macam yaitu gerak melangkah dan gerak melompat (Joseph, 2005: 58). Gerak melangkah yaitu gerak nada ke nada lain yang berurutan, gerak nada melodi melangkah dibedakan menjadi 2 yaitu gerak melangkah naik dan turun. Gerak melodi melangkah memberikan kesan rasa tenang. Gerak melompat adalah gerak nada ke nada lain yang tidak berurutan, gerak nada melodi melompat dibedakan juga menjadi 2 yaitu gerak melompat naik dan turun.

Melodi yang terdapat pada lagu Babalu mBatang dalam kesenian Babalu merupakan campuran antara melodi gerak melompat naik dan melodigerak melompat turun sekaligus melodi gerak melangkah naik danmelodi gerak melangkah turun.

4 Aransemen Musik Iringan Kesenian Babalu

Aransemen adalah gubahan lagu untuk orkes atau kelompok paduan musik, baik vokal maupun instrumenal (Banoe 2003: 30).Jadi aransemen adalah mengubah lagu dengan penyesuaian komposisi musik yang telah ada sehingga esensi musik tidak berubah.Dalam kesenian Babalu, aransemen digunakan untuk melengkapi karya agar dinikmati semakin menarik.

Menurut Kawakami (1975:260) ada beberapa elemen yang membentuk struktur itu antara lain : introduksi, chorus, interlute, variasi, ending, dan vamp.

\subsection{Intro}

Musik dalam Kesenian Babalu mayoritas didominasi oleh alat musik ritmis, yaitu rebana, tamborin, kentongan, ketuk, dan kendang. Suara yang terdengar terkesan ramai. Pola yang digunakan tiap alat musik tidak banyak, karena tiap alat musik biasanya hanya memakai pola yang sama diulangulang sampai lagu selesai. Seumpama ada perbedaan pola dalam satu alat musik, hanya ada perbedaan pola ketika awal dan akhir lagu saja. Rebana memiliki 2 pola irama yang berbeda di dalam intro lagu Babalu mBatang. Hal ini di karena kesan irama rebana cenderung kearah keislaman yang berakar pada budaya daerah setempat. Berikut adalah 2 birama pola irama intro dalam kesenian Babalu dengan judul Babalu MBatang

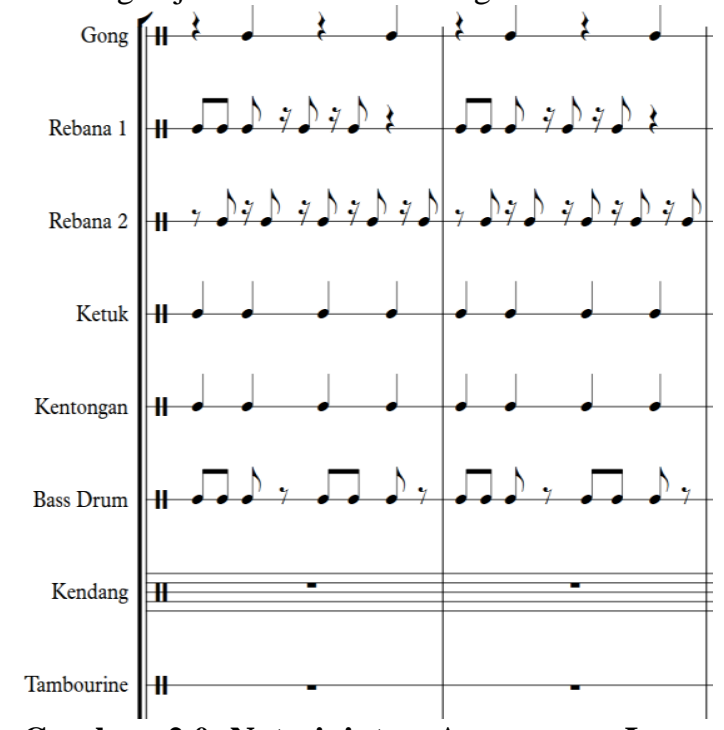

Gambar 2.0 Notasi intro Aransemen Lagu Babalu Mbatang

Dalam gambar diatas, peneliti menyimpulkan pola ritmis rebana 1 dan rebana 2 berbeda.Hal ini dikarenakan rebana 1 dan rebana 2 memberikan efek ramai pada saat intro. Selain itu pola irama rebana 2 juga mengisi kekosongan tanda istirahat pola irama rebana 1. Jadi pola irama rebana 2 memberikan efek pelengkap sebagai pola irama rebana1.Selain itu pola irama ketuk dan pola irama kentongan mempunyai pola irama yang sama. Pola irama ketuk dan kentongan itu memang disamakan bagian intro 
karena kedua instrumen tersebut memberikan warna yang berbeda karena dari bahan yang berbeda. Dalam keterangan yang sudah dipaparkan, pola irama kentongan dan ketuk mempunyai pola irama yang sama di intro pertama walaupun kedua instrumen tersebut terbuat dari bahan yang berbeda. Selain itu pola irama yang sama juga menambah efek nuansa yang berbeda dan mempertebal bunyi.Selain itu pola irama bass drum berbeda dari pola irama alat musik ritmis yang lain.

\subsection{Verse 1}

Irama yang di pakai didalam model iringan tunggal dengan model iringan rangkap berbeda karena dalam proses pembuatannya pembuat aransemen menyesuaikan gerak tari yang sudah ada sejak jaman dahulu. Dalam penjelasan dari narasumber Verse yang digunakan model iringan santai biasanya menggunakan irama yang rata sebab irama yang rata merupakan iramadengan pembagian yang rata atau sama atas pulsanya.

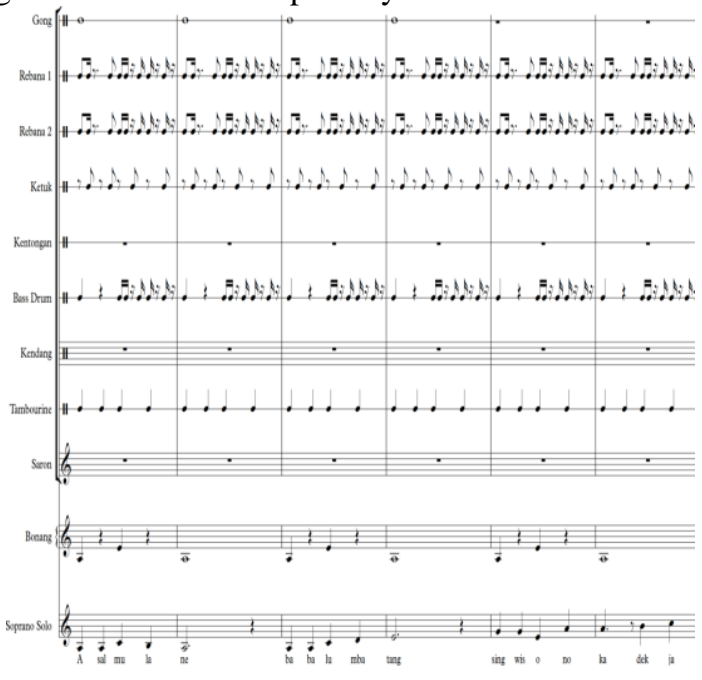

Gambar 3.0 Notasi Verse 1 Lagu Babalu Mbatang

Dari data yang peroleh peneliti, musik iringan tunggal dalam kesenian Babalu dengan judul Babalu MBatang mayoritas didominasi oleh alat musik ritmis yaitu rebana1, rebana 2, ketuk, kentonganm dan bass drum. Suara yang terdengar terkesan agak monoton namun seimbang karena pola ritmis rebana 1 dan rebana 2 memiliki pola ritmis yang sama.Pola yang digunakan tiap alat musik tidak banyak, karena tiap alat musik biasanya hanya memakai pola yang samadiulangulang sampai musik iringan tunggal selesai.

\subsection{Verse 2}

Musik iringan rangkap pada verse 2 itu mempunyai kesan ramai karena pola ritmis tiap-tiap instrumen saling berkesinambungan saling melengkapi dan memiliki pola yang berbeda. Dalam keterangan diatas, model musik iringan rangkap kesenian Babalu memiliki pola ritmis yang berbeda. Jadi bisa dikatakan pola irama yang dipakai dalam musik iringan rangkap mempunyai pola irama tak rata

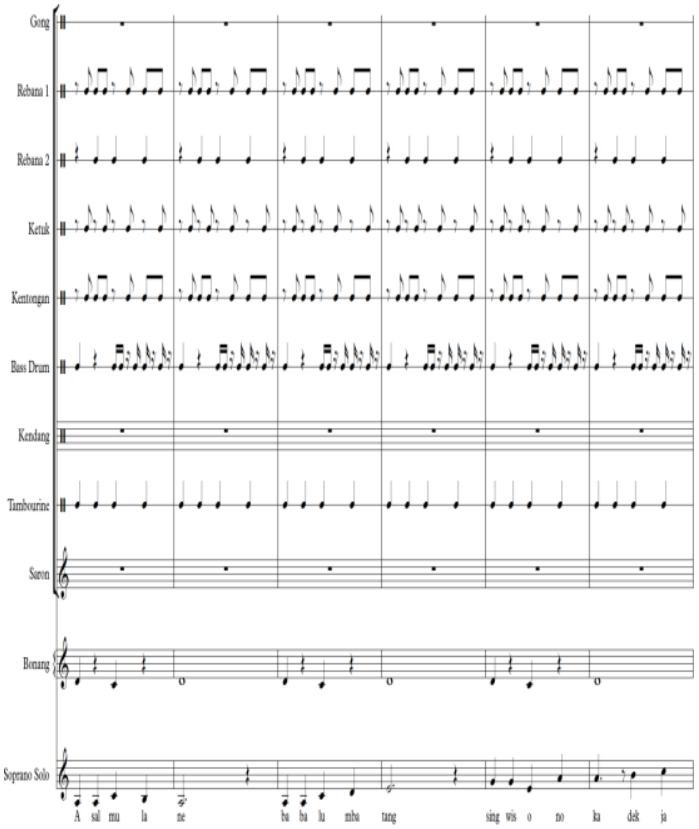

Gambar 4.0 Notasi Verse 2 Lagu Babalu Mbatang

Dari data yang peroleh peneliti, musik iringan rangkap dalam kesenian Babalu dengan judul Babalu MBatang masih mayoritas didominasi oleh alat musik ritmis yaitu rebana1, rebana 2, ketuk, kentongan dan bass drum. Namun suara yang terdengar terkesan ramai karena pola ritmis rebana 1 dan alat musik yang lain memiliki pola ritmis yang berbeda. Pola yang digunakan tiap alat musik juga tidak banyak, karena tiap alat musik biasanya hanya memakai pola yang samadiulang-ulang sampai musik iringan rangkap selesai.

\subsection{Reff}

Reff dalam bagian kesenian Babalu mempunyai makna tentang kesederhanaan dalam menjalani kehidupan. Walaupun tentang kesederhanaan namun mempunyai keistimewaan yang filosofi didalamnya mengacu kepada lirik lagunya. Reff merupakan bagian yang mudah di ingat bagi para pendengar karena Reff merupakan bagian inti atau tujuan dari lagu tersebut. 


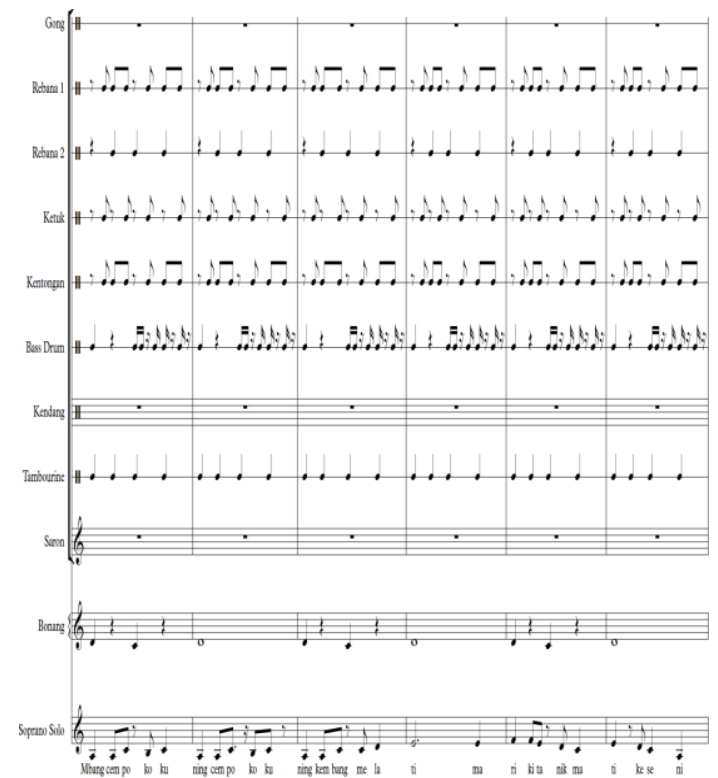

\section{Gambar 5.0 Notasi Reff Lagu Babalu Mbatang}

Dari data yang peroleh peneliti, Reff dalam kesenian Babalu dengan judul Babalu MBatang masih mayoritas didominasi oleh alat musik ritmis yaitu rebana1, rebana 2, ketuk, kentongan dan bass drum. Namun suara yang terdengar terkesan ramai karena pola ritmis rebana 1 dan alat musik yang lain memiliki pola ritmis yang sama.Pola yang digunakan tiap alat musik juga tidak banyak, karena tiap alat musik biasanya hanya memakai pola yang sama diulang-ulang sampai reff selesai.

\subsection{Ending}

Ending adalah bagian terakhir. Selain itu, dalam mengaransemen suatu karya, perlu juga memahami unsur-unsur musikal yang diantaranya ritme, melodi, harmoni, tempo, dan dinamik. Dalam penjelasan diatas Ending merupakan bagian akhir sebuah karya musik. Ending juga berfungsi agar lagu berakhir lancar, smooth (mulus), dan tidak berhenti secara mendadak.Biasanya ending menampilkan ciri khas dan mempunyai unsur klimaks.

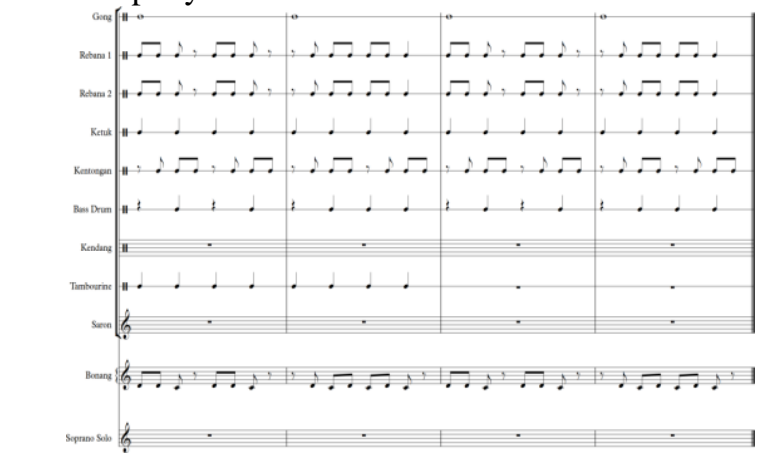

Mbatang
Dari data yang peroleh peneliti, Ending dalam kesenian Babalu dengan judul Babalu MBatang mayoritas didominasi oleh alat musik ritmis yaitu rebana1, rebana 2, ketuk, kentongan dan bass drum. Suara yang terdengar terkesan monoton namun seimbang karena pola ritmis rebana 1 dan rebana 2 memiliki pola ritmis yang sama.Pola yang digunakan tiap alat musik tidak banyak, karena tiap alat musik biasanya hanya memakai pola yang samadiulangulang sampai musik iringan tunggal selesai.

\subsection{Instrumen}

alat musik yang digunakan dalam musik iringan kesenian Babalu dulu adalah bonang barung,saron,demung,kentongan,rebana,gong,kendan $\mathrm{g}$, tamborin,dan ketuk. Rebana, ketuk, bass drum, simbal, kentongan dan tamborin digunakan sebagai alat musik ritmis yang mengiringi musik iringan Babalu.saron di gunakan sebagai alat musik melodis. Instrumen kempul dan gong digunakan sebagai penguat pada akhir birama atau iringan musik atau lagu.Sedangkan instrumen kendang digunakan untuk mengiringi gerakan pada tarian Babalu.

\subsection{Tempo}

Tempo kesenian Babalu mengalami 3 kali proses pergantian. Intro kesenian Babalu dengan lagu Babalu mBatang menggunakan tempo $110 \mathrm{MM}$. Tempo tersebut termasuk dalam tempo cepat. Namun dalam verse 1 (musik iringan tunggal) menggunakan tempo 60MM yang termasuk dalam tempo lambat, akan tetapi verse 2, reff dan ending kembali menggunakan tempo 110MM.

\subsection{Tanda Dinamik}

lagu-lagu yang terdapat dalam KesenianBabalu mayoritas adalah lagu yang menggunakan dinamik kuat/ keras forte, terutama alat-alat musik ritmisnya, walaupun ada juga beberapa bagian lagu yang menggunakan dinamik mezzo forte (agak kuat) dan mezzo piano (agak lembut), tetapi sampai saat ini tidak ada satupun lagu yang menggunakan dinamik lembut.

\subsection{Tanda Ekspresi}

Kesenian Babalu termasuk dalam kesenian tradisional/ kesenian daerah, sehingga dalam Kesenian Babalu tidak menggunakan part musik sebagai pendukung dalam memainkan musiknya, maka dalam Kesenian Babalu tidak menggunakan tanda ekspresi.Dalam penjelasan diatas, kesenian Babalu adalah kesenian daerah jaman dahulu yang pada saat itu belum ada partitur musik.Oleh karena itu dalam kesenian Babalu dengan judul lagu Babalu mBatang tidak menggunakan tanda ekspresi.

\subsection{Tanda Birama}

Berdasarkan penelitian dan teori di atas, pemakaian tanda birama lagu-lagu yang terdapat dalam Kesenian Babalu semuanya sama, yaitu 4/4 (empat per empat), karena sampai saat ini peneliti 
belum menemukan lagu-lagu dalam Kesenian Babalu yang menggunakan tanda birama/ metrum selain tanda birama/ metrum 4/4 (empat perempat). Tanda birama 4/4 (empat per empat) mempunyai arti bahwa setiap birama berisi empat ketukan dengan satuan titinada ketukan 1/4 (satu per empat). Maka, berdasarkan teori yang dikemukakan di atas, tanda birama/ metrum pada lagu-lagu dalam Kesenian Babalu tergolong dalam jenis tanda birama sederhana dengan klasifikasi birama sederhana empat.

\section{KESIMPULAN DAN SARAN}

Komposisi musik iringan Babalu pada lagu Babalu mbatang mempuanyai bentuk 1 bagian. Tangga nada yang dipakai diatonic pelog dan menggunakan pola nada minor melodis. Syairnya menggunakan bahasa jawa ngoko. Irama pada komposisi kesenian Babalu menggunakan irama rata. Gerak melodinya campuran antara melodi gerak melompat naik dan melodi gerak melompat turun sekaligus melodi gerak melangkah naik dan melodi gerak melangkah turun. Tempo pada kesenian Babalu adalah $120 \mathrm{MM}$ atau biasa disebut allegro moderato

Aransemen musik iringan Babalu pada lagu Babalu mbatang : 1) Intro mempunyai pola iringan tunggal, pola irama rata dan menggunakan tempo 110MM. 2) Chorus terdapat 2 bagian, pada bagian 1 menggunakan iringan tunggal, pola irama rata dan menggunakan tempo 60MM, namun pada bagian 2 menggunakan iringan serempak, pola irama tak rata dan menggunakan tempo 110MM. Iringan tunggal mempunyai pola irama rata, dan iringan serempak menggunakan pola irama tidak rata. 3) Di dalam lagu Babalu mbatang tidak mempunyai interlude 4) Reff menggunakan iringan serempak dan pola irama tidak rata. 5) Ending menggunakan iringan tunggal dan pola irama rata. 6) Harmoni pada lagu Babalu mbatang menggunakan close harmoni. 7) Instrumen Babalu menggunakan rebana, kendang, kentongan, bonang, ketuk, saron, tamborin, bass drum, simbal. Alat musik Babalu didominasi alat musik ritmis karena pada jaman dahulu di kabupaten batang masih belum ditemukan alat musik modern. 8) Tanda dinamik menggunakan dinamik mezzo forte. 9) tanda birama pada lagu Babalu mbatang menggunakan 4/4

\section{DAFTAR PUSTAKA}

Arikunto, S. 1999. Prosedur Penelitian. Jakarta : PT. Bina Aksara.

Arikunto, S. 1983. Prosedur Penelitian suatu Pendekatan Praktis, Jakarta : Bina Aksara.

Almanzur Fauzan dan Ghony Djunaidi. M 2012, Metode Penelitian Kualitatif, Yogyakarta : AR Ruzz Media.
Bastomi, S. 1998. Apresiasi Kesenian Tradisional. Semarang : IKIP Semarang.

Bastomi, Suwaji. 1990. Wawasan Seni. Semarang: IKIP Semarang.

Budhi, F.P. (2011). Bentuk Pertunjukkan dan Makna simbolis Kesenian Babalu.

Depdikbud. 1984. Kamus Istilah Antropologi. Jakarta : Pustaka Pembinaan dan

Pengembangan Bahasa.

Depdikbud.

Hayat, Edi. 2005. Perempuan Multikultural. Jakarta : Desantara

Jazuli, M. 1994. "Telaah Teoritis Tari". Semarang: IKIP Semarang Press.

Jazuli, 2001. Paparan Mata Kuliah Teori Kebudayaan. Diklat Jurusan Seni Drama Tari dan Musik Fakultas Bahasa dan Seni Universitas Negeri Semarang. Tidak Diterbitkan.

Yogyakarta : Lentera

Koentjaraningrat. 1990. Kebudayaan Mentalis dan Pembangunan. Jakarta: PT Gramedia Pustaka Utama.

Maryoto. 1989. Sejarah Musik. Yogyakarta : Pusat Musik Liturg Musik

Meriam, Alan P.1964,1987.Ihe Anthropologlt of

Moleong, J. Lexy. 1994. Metodologi Penelitian Kualitatif. Bandung : PT. Remaja Rusda Karya.

Musik Fakultas Bahasa dan Seni Universitas Negeri Semarang. Tidak Diterbitkan.

Prihatini Sri Nanik. 2008, Seni Pertunjukan Rakyat Kedu, Surakarta : Pascsarjana dan ISI Press Surakarta.

Prayitno. 1990. Pengantar Pendidikan Seni Tari. Jakarta: Dekdibud Dirjen Dikti

Sedyawati, Edi. 1981. Pertumbuhan Seni Pertunjukan. Jakarta : Sinar Harapan.

Paparan Mata Kuliah Teori

Kebudayaan. Diklat Jurusan Seni Drama Tari dan Musik Fakultas Bahasa dan Seni Universitas Negeri Semarang. Tidak Diterbitkan.

Sunarko, Hadi. 1985. Seni Musik. Klaten : PT Intan Pariwisata

Shadily, Hasan. 1986. Ensiklopedia Indonesia. Jakarta : Lethiar Abnuyan Have.

Supanggah, Rahayu. 2012. Bothekan Karawitan.

Soedarsono, R. M. 1992. Pengantar Apresiasi Seni. Jakarta: Balai Pustaka

Soewito. 1996. Teknik Termudah Belajar Olah Vokal. Jakarta: Titik Terang

Takari Muhammad, Yusliyar, Yose firdaus, etc. 2008. Karya Musik Dalam Konsep Seni Pertunjukan. Jurnal etnomusikologi. Medan. 
Isbah, Faliqul. Wiyoso, Joko. JURNAL SENI MUSIK 8 (1) (2019)

Yeniningsih Kurnita Taat 2007, Nilai-nilai budaya dalam kesenian tutur Mptoh, Harmonia Vol VIII, Semarang. 